\title{
A novel ultrasound guided approach for lumbar periradicular injections with investigating the radicular artery nearby (IRAN) technique
}

\section{Objectives}

The object of this study is to introduce a novel USG approach for lumbar periradicular injections by investigating radicular artery nearby (IRAN) technique and to assess the feasibility and preliminary means by fluoroscopy.

Study design: The USG periradicular injection is performed under real time imaging. An axial scanning view is obtained through identifying the spinous processes, lamina, zygapophyseal joints and transverse processes.

Setting: The curve probe put transversally and the needle site check in axial and sagittal view.

Methods: The IRAN technique was defined by sliding probe a little lower under the facet joint in sagittal plane to view the pulse of nearby radicular artery by Doppler or Pulse Echo. Then spinal needles are advanced with in-plane technique toward the artery until touch the nearby bone.

Results: Fluoroscopy examination confirms that the needle tip is correctly placed under the pedicle along the nerve root and lateral to the pars interarticularis with no intravascular injection.

Limitation: Although searching for small vessels is difficult in cadaver studies, the IRAN technique would be confirmed in the future on Cadaver.

Conclusion: The IRAN technique as a new anatomic landmark allow an easy and corrected periradicular placement of the needle.

Keywords: ultrasound, spine, injection, intervention and radicular artery
Volume I2 Issue I - 2020

Helen Gharaei
Anesthesiologist, Pain Fellow MD-FIPP, Azargan Pain Clinic, Iran

Correspondence: Helen Gharaei, Anesthesiologist, Pain Fellow MD-FIPP, Azargan Pain Clinic,Vanak Sq, North Gandi St, Sanaie St, No 26, Ist flour, Tehran, Iran, Tel +989|29306577, Email helengharae@gmail.com

Received: December 23, 2019 | Published: January 22, 2020

\section{Introduction}

Ultrasound as a portable and accessible device has attracted the attention of pain specialists and is now used for spine injections. As spine injection is more difficult compared to other pain injection techniques, it did not find a routine place in practice. But the transforaminal injection(TF) is still challenging and pain interventionists are always searching for new techniques to decrease the chances of intravascular injection. Intravascular injection has always been a barrier when it comes to choosing ultrasound as a sole modality for spine injection.

According to the Article review in 1971, Bogin and Stulin were the first anesthesiologist who used ultrasound to perform the lumbar puncture and central neuraxial intervention. ${ }^{1}$ Then Cork et al were the first group of anesthesiologists who used ultrasound to locate the landmarks relevant to epidural anesthesia in $1980 .^{2}$ Currie JM and Wallace DH et al described the neuraxial sonoanatomy and the measurement of the depth in $1984 \& 1992 .^{3,4}$ The utility of the USG for epidural injection (the optimum window, thoracic epidural space, improving learning curve and combining spinal-epidural) was under investigation by Grau et al. This group refer to Doppler imaging as a modality to provide information regards to the position of vessels in the needle trajectory which could help to reduce complications in lumbar spine injection between 2001 to $2004 .^{5-10}$ Real-time USG paramedian epidural access with in-plane approach was described in 2009 by Karmakar in HongKong. ${ }^{11}$

After the epidural space, it was the facet $(Z)$ joint injection which was considered for USG injection by pain interventionists. In 1997, Kullmer K et al. described the USG lumbar Z joint injection ${ }^{12}$ and the method was later validated with computed tomography-controlled in 2007 by Galiano et al. ${ }^{13}$ However, lumbar facet nerve injection or lumbar medial branch block was described later by Greher $\mathrm{M}$ et al. in 2004 and oblique out -of- plane technique of L5 dorsal ramus was outlined in $2015 .{ }^{14,15}$

Due to the complexity of TF procedure, it was later started in 2005 and was considered by Galiano $\mathrm{K}$ et al. ${ }^{16}$ who described lumbar TF injection by founding the neural foramen with the in-plane approach in axial view. The technique was then improved by the help of A. Loizides in $2011 .{ }^{17}$ who described a new in-plane approach in sagittal view by positioning the transducer perpendicularly over the medial part of the respective transverse processes, depicting the hyperechoic inter transverse ligament. Both techniques were in fact TF injection and not periradicular injection.

In particular, the most challenging part of USG lumbar injection is TF injection and although it is briefly discussed by authors, due 
to its complication of the intravascular injection it is not routinely used. The objective of this study is to introduce a novel USG approach for lumbar periradicular injections by investigating radicular artery nearby (IRAN) technique and to assess the feasibility and preliminary means by fluoroscopy.

\section{Methods}

The ultrasound examinations and intervention were performed on a standard device with a broadband 9- to 4- $\mathrm{MHz}$ curved array transducer. Ultrasound examination of lumbar spine including sonoanatomy before injection is performed in 4 major steps:

\section{Step I}

The first step in USG spine injection is to determine the vertebral level. For this propose, put the curve probe longitudinally in the paraspinal space (about $4 \mathrm{~cm}$ ) on the ribs; notice the difference between the rib and transverse process(TP) view. The rib length is longer and the TP are about the same size with hyperechoic tip and finger-like acoustic shadow down (Figure 1). Move probe down towards the sacrum, notice superior articular process of sacrum (SAP S1) at the end and do not mistake it with TP L5.Place the desired level in the middle of the probe and screen (depth about $9 \mathrm{~cm}$ ), then rotate the probe 90 degrees clockwise transversally. By moving the probe upward down, you will get different axial views of the vertebra. For spine injections, you need to look for a clear view of the spinal canal. In this view, spinous process is at the midline and lamia and $\mathrm{Z}$ joint (by dedicating its wavy appearance with two layers of superior and inferior articular process ( SAP\&IAP) )and TP are more visible laterally (Figure 2).

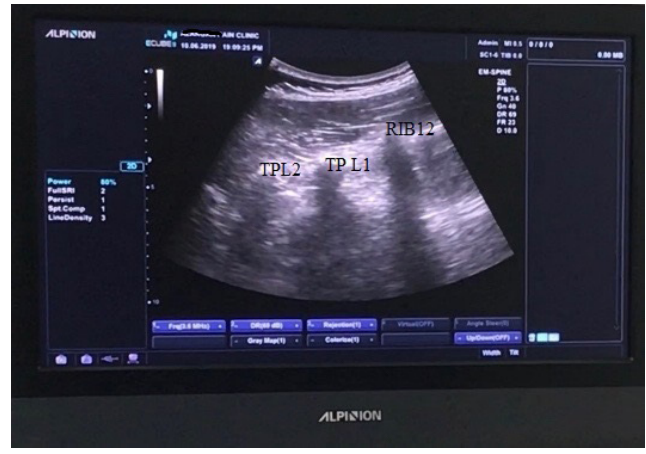

Figure I Sagittal scanning of I2Rib and transverse process (TP) of LI \&L2

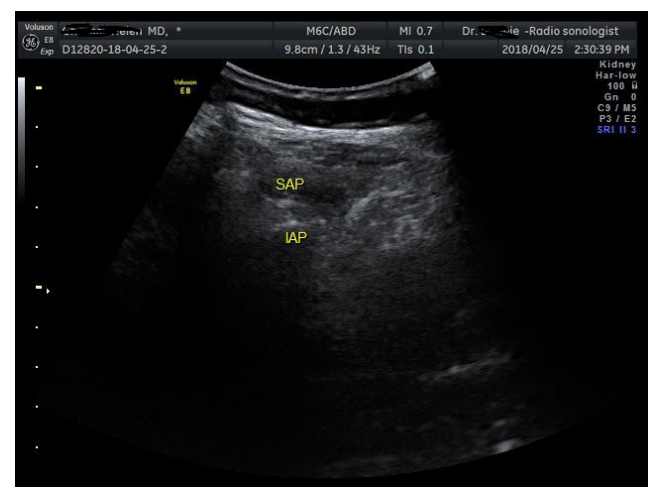

Figure 2 Axial scanning of facet joint with superior and inferior articular process (SAP\&IAP).

\section{Step2}

The second step is to find four parallel sagittal lines: put the curve probe longitudinally in the midline of the upper lumbar spine to find the horse shape appearance of spinous process; sliding the probe to the sacrum to find the inter spinous process line with a different view of spinous process and a hypoechoic gap which is useful for spinal and epidural injections.

Move probe $1-1.5 \mathrm{~cm}$ laterally on paramedian or interlaminar line to find a hypoechoic gap between lamina as a window for epidural block and

then sliding probe on axial scanning $3-4 \mathrm{~cm}$ laterally to find the camel hump shape inter pedicular or articular line which in contrast to other lines is continuous without a gap and is useful for confirming the needle tip position in $\mathrm{MBB}$ and periradicular block.

By sliding probe on axial scanning more laterally $4-5 \mathrm{~cm}$, the probe would be on TP .By turning the probe 90 degree clockwise longitudinally inter-transverse process line will become visible in sagittal plane with a widen hypoechoic gap between TP which is most useful for vertebral counting (Figure 3).

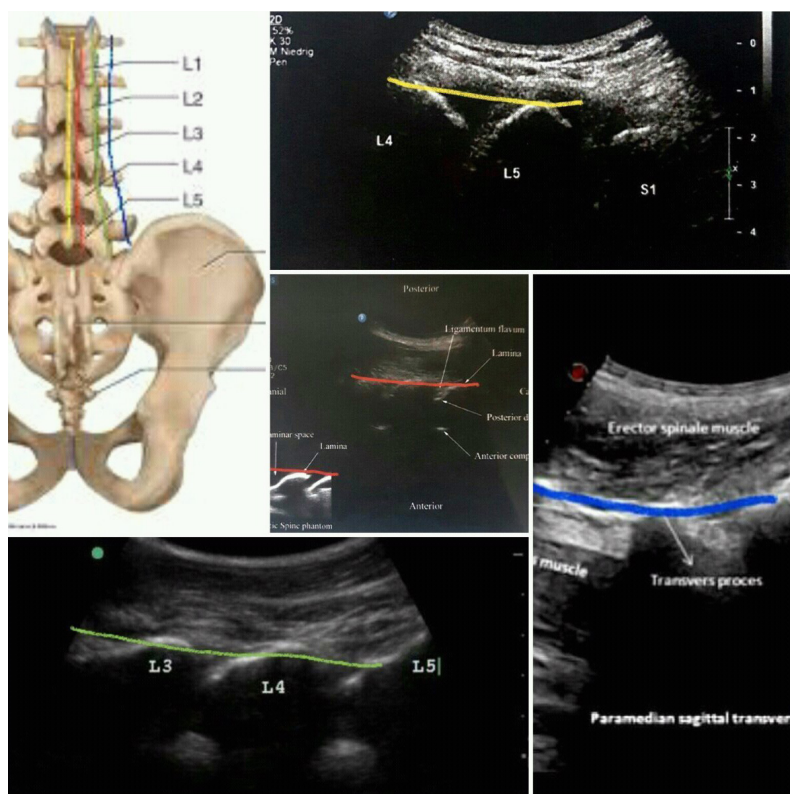

Figure 3 Sagittal scanning of the spine on spinous processes (yellow line), interlaminar line (red line), inter pedicular line (green line) and inter transverse line (blue line).

\section{Step3}

Put the probe transversally on desire lumbar level, then sliding it laterally in axial plane over the $\mathrm{Z}$ joint. By sliding and tilting probe a little lower in sagittal plane, search for the pulse of artery under the $Z$ joint by Doppler or the Pulse- Echo method. Measuring the depth of skin to artery for estimating distance to goal (Figure 4).

\section{Step4}

With the in-plane technique, a spinal needle is advanced under real-time scanning towards the artery until touching the nearby bone. If the needle is not able to touch the bone at the estimated depth, the needle might be in intervertebral foramen (IVF), so push the 
needle out and redirect it. Then turn probe longitudinally 90 degrees clockwise on inter pedicular line or inter transverse line to confirm its position under transverse process. One $\mathrm{ml}$ of contrast agent was subsequently injected under live fluoroscopy to rollout intravascular injection. Needle site also confirm in lateral fluoroscopy (Figure 5,6).

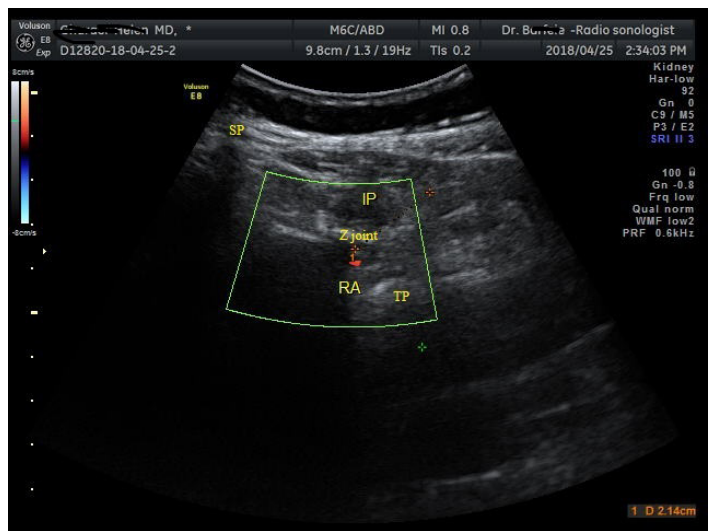

Figure 4 Doppler axial scanning of the pulse of nearby radicular artery (RA, red dot) under the $Z$ joint.

SP, spinous process; IP, injection point **;TP, transverse process.

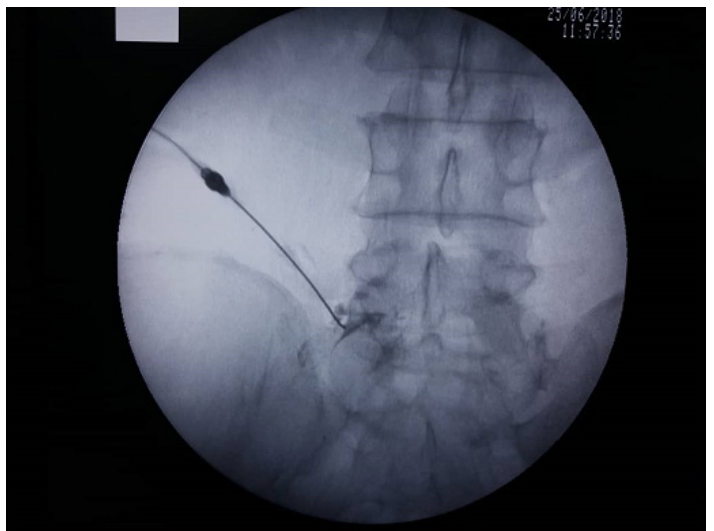

Figure 5 Anteroposterior fluoroscopy of the needle trajectory and root after contrast injection.

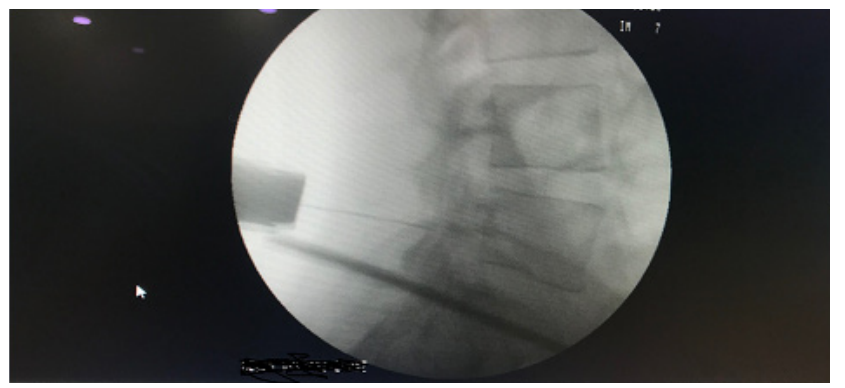

Figure 6 Lateral fluoroscopy of needle position lateral to the pars interarticularis.

\section{Results}

Fluoroscopy examination confirms that the needle tip is correctly placed under the pedicle along the nerve root in AP \& lateral fluoroscopy with no intravascular injection. Although in cadaver studies, searching for vessels is difficult, I hope the IRAN technique would be confirmed in future on Cadaver.

\section{Discussion}

The most common method for diagnosing the radicular pain is selective nerve root block that is characterized by the diffusion of injections along the nerve root but not the epidural space as opposed to the TF injection that is confirmed by injection into the epidural space. Although most of the times both blocks are used interchangeably. ${ }^{18,19}$ The TF injection is still challenging and pain interventionists are always searching for new techniques to decrease the chances of intravascular injection. The intervertebral foramen (IVF) is a hole located between the two adjacent vertebrae that allow communication between the spinal canal and the external area. Although, it is used as a pathway through the spinal nerve roots, vascular structures follow the same path. Knowledge of these vessels and the origin of the feeding arteries are essential for interventional procedures.

The underlying vascular structure consists of two separate segmental vessels left and right that arise from the posterior surface of the aorta. These lumbar arteries divides into several branches reaching the level of the IVF. Three medially directed branches arise from the spinal ramus branch of the lumbar segmental artery (SA). These are the anterior spinal canal branch $(\mathrm{AB})$, the posterior spinal canal branch $(\mathrm{PB})$ and the neural branch $(\mathrm{NB})$ which are separated into anterior and posterior radicular artery (AR\& PR) that feed the ventral and dorsal roots (Figure 7). Some radicular arteries regress while others grow larger. The radicular arteries that are very small become lost along the roots before reaching the spinal cord. ${ }^{20}$ Radicular arteries can sometimes be replaced functionally by segmental radiculomedullary arteries. However, unlike those arteries, radicular arteries do not form anastomosis with the anterior or posterior spinal arteries. What we really see in IRAN technique out of foramen (under pedicle and lateral to the pars interarticularis) is SA or SR and not RA (Figure 8).

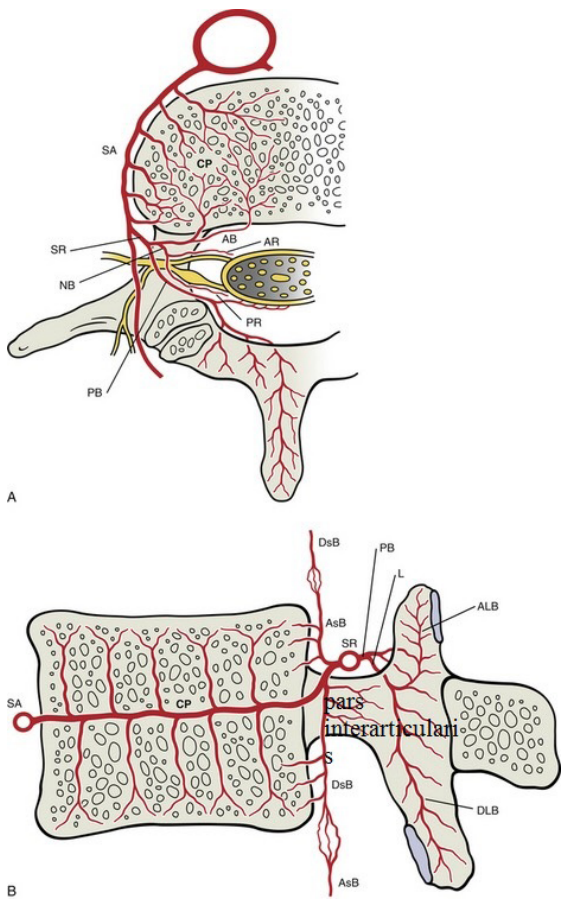

Figure 7 Arterial supply to a lumbar vertebra, horizontal section (A) and midsagittal section (B) SA, segmental artery; SR, spinal ramus; AB\&PB, anterior \& posterior branches; NB, neural branch; AR\&PR: anterior \& posterior radicular arteries; AsB \&DsB, Anterior branch ascending \&descending branches; L, laminar;ALB\&DLB, laminar ascending \&descending branches. 


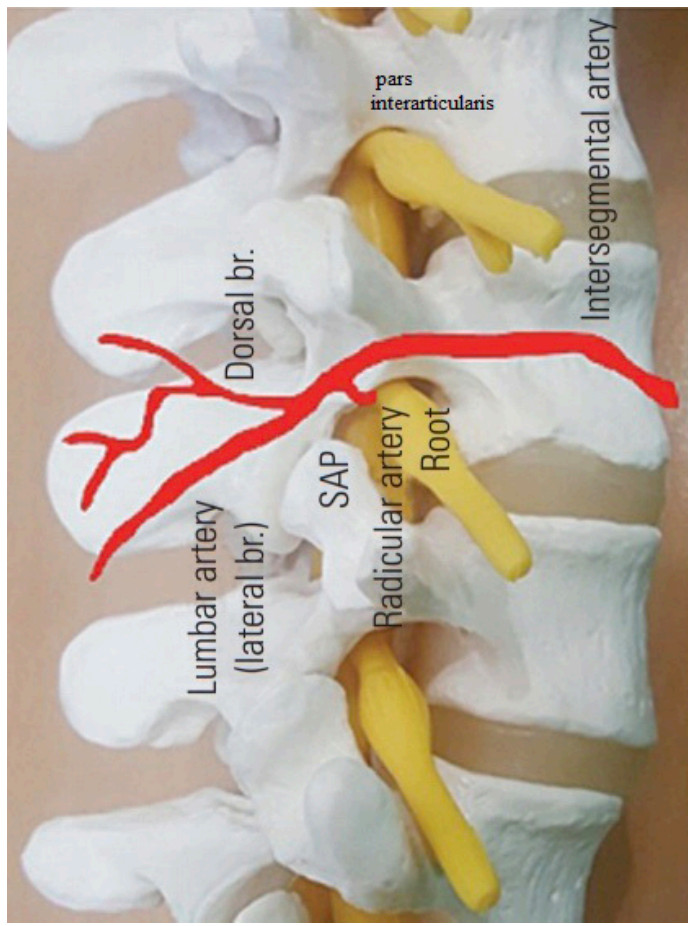

Figure 8 Schematic representation of nerve root and accompanying artery on the pars interarticularis.

The most important radiculomedullary is the Adamkiewicz (AK) artery which are found mainly in the region of the dorsolumbar junction. The $\mathrm{AK}$ is sometimes called greater radicular artery of $\mathrm{AK}$, however it is in fact a segmental artery. The location of AK within the IVF is important. Neurologic deficit can occur when the blood supply to the spinal cord compromise and presented as anterior spinal artery syndrome. Spinal cord ischemia and stroke occurring during the TF injection may result from the arterial embolization with air or particulate steroids or from direct vessel injuries such as spasm, laceration, and dissection. ${ }^{21}$

TF injection is performed using 3 techniques: classical or supraneural (subpedicular), retroneural and retrodiscal or infraneural techniques. In the classical or sub-pedicular technique, the needle insertion is under the pedicle and above the SAP through the safe triangle area. In the retroneural technique (periradicular or selective nerve root block), needle insert lateral to lamina and lower to TP along the lateral border of the nerve and in the kambin's triangle technique the needle position is lateral to the upper two-thirds of the SAP (suprapedicular) (Table 1).

The safe triangle zone is in fact not safe. The kambin's triangle method seems to be safer but recently, there have been prospective studies showing a relatively high rate of inadvertent intradiscal injections with this technique. There are also concerns about intrathecal and vascular injections during this performance. ${ }^{22,23}$ Retroneural approach may help to avoid intravascular injection due to placing the needle lateral to the exiting nerve root and farther from IVF. There is a fluoroscopic retroneural approach where the needle is placed posterior or posteroinferior within the foramen and is relatively parallel to the dorsal root ganglion or nerve root at the upper portion of the SAP, closer to its lateral edge. ${ }^{24}$ It should wrap around the upper half of the SAP and the line formed between the lateral at the midpoint of the superior and inferior pedicles. The preganglionic approach is another retroneural approach and the objective is to position the needle tip which is medial and inferior to that used in the classic approach, just lateral to the pars interarticularis on the oblique fluoroscopy view. There is no significant correlation between pain relief and needle tip position retroneural or subpedicular, extraforaminal, junctional or foraminal and the success rate is not dependent upon the distance between the needle tip and the nerve root. $^{25,26}$

Table I Comparison of Transforaminal injection approaches

\begin{tabular}{|c|c|c|c|}
\hline $\begin{array}{l}\text { Transforaminal injection } \\
\text { approaches }\end{array}$ & Needle tip & Goal & Contrast spread \\
\hline $\begin{array}{l}\text { Classical or supraneural } \\
\text { (subpedicular) }\end{array}$ & $\begin{array}{l}\text { under the pedicle and above the } \\
\text { SAP }\end{array}$ & Safe triangle area & $\begin{array}{l}\text { Irregular line pattern along the } \\
\text { nerve root which extend into the } \\
\text { anterior epidural space }\end{array}$ \\
\hline $\begin{array}{l}\text { Retroneural ,periradicular or } \\
\text { selective nerve root block }\end{array}$ & $\begin{array}{l}\text { lateral to lamina and lower to } \\
\text { transverse process }\end{array}$ & Lateral border of the nerve & $\begin{array}{l}\text { Irregular line pattern along the } \\
\text { nerve root which may or may } \\
\text { not extend into the posterior } \\
\text { epidural space }\end{array}$ \\
\hline $\begin{array}{l}\text { Retrodiscal or infraneural } \\
\text { techniques }\end{array}$ & $\begin{array}{l}\text { lateral to the upper two-thirds } \\
\text { of the sap (supra-pedicular) }\end{array}$ & Kambin's triangle & $\begin{array}{l}\text { Irregular line pattern in lateral } \\
\text { border of the intervertebral disc } \\
\text { which extend into the anterior } \\
\text { epidural space }\end{array}$ \\
\hline $\begin{array}{l}\text { Ultrasound guided IRAN } \\
\text { technique }\end{array}$ & $\begin{array}{l}\text { lateral to lamina and lower to } \\
\text { transverse process, just lateral to } \\
\text { the pars interarticularis }\end{array}$ & Nearby radicular artery & $\begin{array}{l}\text { Irregular line pattern along the } \\
\text { nerve root which may or may } \\
\text { not extend into the posterior } \\
\text { epidural space }\end{array}$ \\
\hline
\end{tabular}

The IRAN technique is an example of the retroneural or periradicular technique which is done under USG and the needle tip is nearby radicular artery and far from it, lateral to lamina and lower to transverse process.
Even though the vessels are visible by ultrasound, it is advisable to inject a contrast agent at the end of the IRAN procedure and take a live or real-time fluoroscopy to rollout the intravascular injection. (Intravascular contrast injection is typically not seen on single shot 
fluoroscopy imaging because the contrast material is rapidly diluted in the bloodstream). In case of do not access to fluoroscopy, first inject a test dose (e.g. normal saline) and look at its distribution with Doppler on the ultrasound screen (if there wasn't any distribution, the injection may be intravascularly) then inject local anesthetic and after confirming patient alertness inject the non-particulate steroid. Although searching for small vessels is difficult in cadaver studies, but this is a limitation of this study and I wish the IRAN technique would be confirmed in the future on Cadaver.

\section{References}

1. Bogin IN, Stulin ID. Application of the method of 2-dimensional echospondylography for determining landmarks in lumbar punctures. Zh Nevropatol Psikhiatr Im S S Korsakova. 1971;71(12):1810-1811.

2. Cork RC, Kryc JJ, Vaughan RW. Ultrasonic localization of the lumbar epidural space. Anesthesiology. 1980;52(6):513-516.

3. Currie JM. Measurement of the depth to the extradural space using ultrasound. Br J Anaesth. 1984;56(4):345-347.

4. Wallace DH, Currie JM, Gilstrap LC, et al. Indirect sonographic guidance for epidural anesthesia in obese pregnant patients. Reg Anesth. 1992;17(4):233-236.

5. Grau T, Leipold RW, Horter J, et al. Paramedian access to the epidural space: the optimum window for ultrasound imaging. J Clin Anesth. 2001;13(3):213-217.

6. Grau T, Leipold RW, Conradi R, et al. Ultrasound imaging facilitates localization of the epidural space during combined spinal and epidural anesthesia. Reg Anesth Pain Med. 2001;26(1):64-67.

7. Grau T, Leipold RW, Conradi R, et al. Ultrasound control for presumed difficult epidural puncture. Acta Anaesthesiol Scand. 2001;45(6):766-771.

8. Grau T, Leipold RW, Horter J, et al. Colour Doppler imaging of the interspinous and epidural space. Eur $J$ Anaesthesiol. 2001;18(11):706-712

9. Grau T, Leipold RW, Conradi R, et al. The visualisation of dura perforation and blood patches with ultrasound. Anasthesiol Intensivmed Notfallmed Schmerzther. 2002;37(3):149-153.

10. Grau T, Leipold RW, Fatehi S, et al. Real-time ultrasonic observation of combined spinal-epidural anaesthesia. Eur $J$ Anaesthesiol. 2004;21(1):25-31.

11. Karmakar MK, Li X, Ho AM, et al. Real-time ultrasound-guided paramedian epidural access: evaluation of a novel in-plane technique. Br J Anaesth. 2009;102(6):845-854

12. Küllmer K, Rompe JD, Löwe A, et al. Ultrasound image of the lumbar spine and the lumbosacral transition. Ultrasound anatomy and possibilities for ultrasonically-controlled facet joint infiltration. $Z$ Orthop Ihre Grenzgeb. 1997;135(4):310-314.
13. Galiano K, Obwegeser AA, Walch C, et al. Ultrasound-guided versus computed tomography-controlled facet joint injections in the lumbar spine: a prospective randomized clinical trial. Reg Anesth Pain Med. 2007;32(4):317-322.

14. Greher M, Scharbert G, Kamolz LP, et al. Ultrasound-guided lumbar facet nerve block: a sonoanatomic study of a new methodologic approach. Anesthesiology. 2004;100(5):1242-1248.

15. Greher M, Moriggl B, Peng PW, et al. Ultrasound-Guided Approach for L5 Dorsal Ramus Block and Fluoroscopic Evaluation in Unpreselected Cadavers. Reg Anesth Pain Med. 201;40(6):713-717.

16. Galiano K, Obwegeser AA, Bodner G, et al. Real-time sonographic imaging for periradicular injections in the lumbar spine: a sonographic anatomic study of a new technique. JUltrasound Med. 2005;24(1):33-38.

17. Loizides A, Gruber H, Peer S, et al. A new simplified sonographic approach for pararadicular injections in the lumbar spine: a CTcontrolled cadaver study. AJNR Am J Neuroradiol. 2011;32(5):828-831.

18. Gharaei H. Transforaminal epidural block or selective nerve root block. EC Anaesthesia. 2015;23:110-112.

19. Gharaei H. Transforaminal epidural block. Anaesth Pain \& Intensive Care. 2013;17(3):223-224.

20. X Demondion, G Lefebvre, O Fisch, et al. Radiographic anatomy of the intervertebral cervical and lumbar foramina (vessels and variants). Diagnostic and Interventional Imaging. 2012;93(9):690-697.

21. Gharaei H. Epidural Steroid Injection Warning \& Safety Recommendations. J Anesth Crit Care Open Access. 2005;2(5).

22. Gharaei H. Is Ultrasound Guided Spine Injection Safe? J of Anes \& Criti Care Open Access. 2018;10(4):131-138.

23. David Levi, Scott Horn, Sarah Corcoran, et al. The Incidence of Intradiscal, Intrathecal, and Intravascular Flow during the Performance of Retrodiscal (Infraneural) Approach for Lumbar Transforaminal Epidural Steroid Injections. Pain Medicine. 2016;17(8):1416-1422.

24. Jie Zhu, Frank JE Falco, Formoso F, et al. Alternative Approach for Lumbar Transforaminal Epidural Steroid Injections. Pain Physician. 2011;14:331-341.

25. Stefan Ignjatovic, Reza Omidi, Rahel A Kubik-Huch. The retroneural approach: an alternative technique for lumbar transforaminal epidural steroid injections. Acta Radiologica. 2018;59(12):1508-1516.

26. Joon Woo Lee, Sung Hyun Kim, Ja-Young Choi, et al. Transforaminal Epidural Steroid Injection for Lumbosacral Radiculopathy: Preganglionic versus Conventional Approach. Korean J Radiol. 2006;7(2):139-144. 